\title{
Densidade de plantas daninhas sob intervenções em três distintas zonas de manejos
}

\section{Weed density under intervention strategies in three different management zones}

\author{
Enza Rigon
}

Universidade Federal de Santa Maria

E-mail: enza-rigon@hotmail.com

OrclD: 0000-0002-5635-8656

Telmo Jorge Carneiro Amado

Universidade Federal de Santa Maria

E-mail: proftelmoamado@gmail.com

OrclD: 0000-0001-8417-9009

Luan Pierre Pott

Universidade Federal de Santa Maria

E-mail: luanpierrepott@hotmail.com

OrcID: 0000-0001-8417-7978

André da Rosa Ulguim

Universidade Federal de Santa Maria

E-mail: andre ulguim@yahoo.com.br

OrclD: 0000-0002-8850-4670

Arthur Kich Buhse

Universidade Federal de Santa Maria

E-mail: arthur.buhse@hotmail.com

OrclD: 0000-0002-5199-7790

Resumo: A ocorrência das plantas daninhas nas áreas agrícolas é dependente, entre outros fatores, do manejo empregado. O objetivo deste trabalho foi avaliar a infestação de plantas daninhas utilizando diferentes intervenções no outono-inverno realizadas em três distintas zonas de manejos. O experimento foi delimitando nas diferentes zonas de manejo, em delineamento de blocos casualizados com três repetições. Os tratamentos foram distribuídos em fatorial. Fator $A$ testou as zonas de manejo alta, média e baixa; enquanto o fator $B$ constou de intervenções para o manejo do solo, sendo eles: pousio, escarificação, policultivos e escarificação+policultivo. A quantificação das plantas daninhas presentes foi realizada dez dias antes da dessecação, através da contagem e identificação das espécies em área de $1 \mathrm{~m}^{2}$. Não se observou interação entre os fatores testados, porém os tratamentos apresentaram diferença entre si quando estudados isoladamente. As menores densidades de plantas daninhas ocorreram na zona de manejo de alta, e a intervenção com menor densidade de plantas daninhas foi escarificação+policultivo. Contudo, o uso de práticas como escarificação e cobertura do solo com policultivos é uma forma de reduzir a densidade de plantas daninhas.

Palavras-chave: pousio, escarificação, policultivo, índice de valor de importância (IVI) 
Abstract: The presence of weeds in agricultural areas depends, among other factors, on the management system. The objective of this study was to evaluate weed infestation using different interventions in autumnwinter carried out in three different management zones. The experiment was delimited in the different management zones, in a randomized block design with three replications. The treatments were distributed in factorial. Factor A tested the high, medium and low management zones; while factor B consisted of interventions for soil management: fallow, chiseling, polyculture and chiseling + polyculture. The weed counting was performed ten days before desiccation, by counting and identifying the species in an area of $1 \mathrm{~m}^{2}$. There was no interaction between the factors tested, but the treatments showed differences between them when studied separately. The lowest weed densities occurred in the high management zone, and the intervention with the lowest weed density was scarification + polyculture. However, the use of practices such as scarification and mulching with polycultures is a way to reduce the weed density.

Keywords: fallow, scarification, polyculture, value index of importance (IVI)

Data de recebimento: $30 / 10 / 2019$

Data de aprovação: 01/06/2020

DOI: https://doi.org/10.30612/agrarian.v13i49.10600

\section{Introdução}

As plantas daninhas distribuem-se aleatoriamente dentro da área de cultivo e causam redução na produtividade da cultura de interesse em função da competição com recursos do meio como luz, água e nutrientes (Pitelli, 2015). A interferência negativa desses vegetais é dependente da espécie e da densidade que ocorre, sendo consideradas problema para diversas culturas (Fialho et al., 2016). As plantas daninhas em competição com a soja promoveram redução de aproximadamente $50 \%$ na produtividade da cultura (Constantin et al., 2009).

A elevada variabilidade genética presente nas plantas daninhas permite sua adaptabilidade à diferentes ambientes, principalmente àqueles com intensa atividade humana (Schneider et al. 2018). Embora o manejo de plantas daninhas tenha evoluído nos últimos anos, elas permanecem a interferir na produção agrícola. Um exemplo da evolução no manejo dessas espécies foi o sistema plantio direto, mediante a imobilização do solo e a cobertura permanente do solo, promovendo supressão na emergência e desenvolvimento e menor densidade de plantas daninhas nos cultivos agrícolas (Silva Hirata et al., 2019), além de ser alternativa para redução do banco de sementes do solo (Lima et al., 2014).

De acordo com São Miguel et al. (2018), a utilização de plantas de coberturas que produzem altos teores de fitomassa reduzem a infestação de plantas daninha, devido ao efeito supressivo da cobertura. Nesse sentido, sistemas integrados de cultivos com alta intensidade de rotação de culturas representam estratégia para mitigar a infestação de plantas daninhas (Ulguim et al., 2018). Assim, o manejo integrado de plantas daninhas prevê o uso de diferentes métodos de controle, apresentando viés econômico e ambiental pelo potencial de redução do uso de herbicidas. Para tanto, o estudo de práticas de manejo auxiliares ao método químico é importante para permitir a redução da infestação de plantas daninhas, permitindo a manutenção da produtividade dos cultivos. Essa abordagem apresenta maior importância dado o atual cenário de resistência de plantas daninhas a herbicidas, totalizando 50 casos em 28 espécies reconhecidos no Brasil (Heap, 2019).

A determinação de zonas de manejo permite ao produtor aliar informações e, consequentemente, manejar a área de acordo com suas condições edáficas, climáticas e da planta, na busca do aumento da eficiência do manejo e produção (Hauschild, 2013). A distribuição e ocorrência das plantas daninhas nas áreas agrícolas assume padrão aleatório, entretanto, praticamos o manejo de forma regular como por exemplo, as aplicações de herbicidas são em área total, e não restritas às áreas ou zonas onde efetivamente as plantas daninhas ocorrem, logo, a divisão das áreas em zonas de manejo facilita a intervenções para que as mesmas sejam mais intensivas. A adoção de técnicas de manejo no período de entressafra que conciliem o controle químico, combinados com o controle cultural, como a utilização de plantas de cobertura de inverno, é parte fundamental para o manejo de biótipos de $C$. bonariensis resistentes à glifosato nos estados da região Sul

Agrarian, Dourados, v. 13, n. 47, p. 405-418, 2020. 
(Oliveira Neto et al., 2010).

Neste sentido, o objetivo deste estudo foi avaliar a infestação de plantas daninhas em função de estratégias de manejo no outono-inverno em três distintas zonas de manejos.

\section{Material e Métodos}

O experimento foi conduzido em área comercial no município de Não-Me-Toque (RS), com coordenadas geográficas $28^{\circ} 28^{\prime} \mathrm{S}$ e $52^{\circ} 46^{\prime} \mathrm{O}$, altitude média da área de $500 \mathrm{~m}$. O clima da região é classificado como Cfa com verão quente (Alvarez et al., 2013). O solo predominante na área é o LATOSSOLO VERMELHO Distrófico típico (Santos et al., 2013). O delineamento experimental utilizado foi o de blocos casualizados, com três repetições. As parcelas experimentais possuíam tamanho de $30 \times 60 \mathrm{~m}$.

A área experimental vinha sendo manejada sob sistema de plantio direto com ferramentas de agricultura de precisão ao longo dos últimos 15 anos, realizando correção de solo e fertilidade em taxa variada, aplicação em dose variada de nitrogênio com base em sensores de vegetação, aquisição de informações como condutividade elétrica do solo, resistência à penetração, mapas de colheita de culturas de verão (soja e milho) e de inverno (trigo). Todas estas informações auxiliaram para a confecção de mapa de zonas de manejo da área através do algoritmo fuzzy c-means, tendo definido três zonas de manejos distintas: zona de baixo, médio e alto potencial produtivo (Figura 1). Após a definição das zonas de manejo, foram realizadas análises física e química do solo, na camada de 0 a $20 \mathrm{~cm}$ de profundidade (Tabelas 1 e 2).

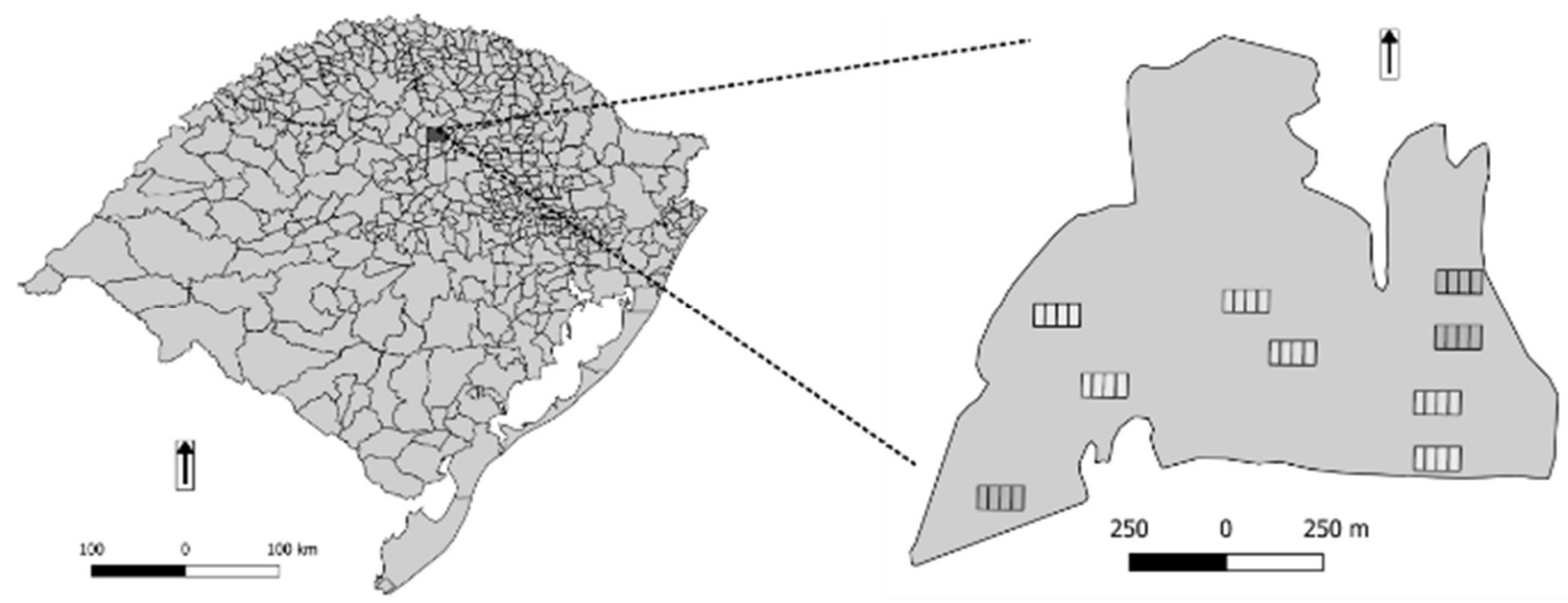

Figura 1. Localização das parcelas experimentais nas zonas de manejo

Tabela 1. Atributos químicos do solo das respectivas zonas de manejo de 0 a $20 \mathrm{~cm}$ de profundidade

\begin{tabular}{ccccccccc}
\hline \multirow{2}{*}{ ZM Atributos } & \multicolumn{1}{c}{$\mathrm{pH}$} & $\mathrm{P}$ & $\mathrm{K}+$ & $\mathrm{SO}_{4}^{-2}$ & $\mathrm{Ca}^{+2}$ & $\mathrm{Mg}^{+2}$ & $\mathrm{Al}^{+3}$ \\
\cline { 2 - 8 } & $1: 1$ & & $\mathrm{mg} \cdot \mathrm{dm}^{-3}$ & & \multicolumn{3}{c}{$\mathrm{cmol.dm-}^{3}$} \\
\hline \multirow{2}{*}{ Zona de baixa } & 5,3 & 24,9 & 121,0 & 7,5 & 4,35 & 2,33 & 0,21 \\
Zona de média & 5,5 & 26,2 & 130,0 & 3.7 & 5,36 & 3,29 & 0,12 \\
Zona de alta & 5,7 & 53,1 & 153,0 & 9.3 & 6,30 & 3,30 & 0,05 \\
\hline
\end{tabular}

Legenda: ZM = zonas de manejo; fósforo (P); potássio (K+); sulfato (SO4-2), cálcio (Ca+2), magnésio $(\mathrm{Mg}+2)$ e alumínio (Al+3). 
Tabela 2. Atributos físicos do solo das respectivas zonas de manejo de 0 a $20 \mathrm{~cm}$ de profundidade

\begin{tabular}{|c|c|c|c|c|c|}
\hline Atributos & Argila & Densidade & Macro & Micro & RP \\
\hline ZM & $\%$ & g. $\mathrm{cm}^{-3}$ & $\%$ & $\%$ & $\mathrm{MPa}$ \\
\hline Zona de baixa & 34,3 & 1,39 & 0,15 & 0,31 & 3.56 \\
\hline Zona de média & 38,7 & 1,28 & 0,18 & 0,32 & 3.22 \\
\hline Zona de alta & 44,6 & 1,26 & 0,19 & 0,34 & 2.56 \\
\hline
\end{tabular}

Legenda: ZM = zonas de manejo; Macro = macroporosidade; Micro = porosidade; RP = resistência à penetração

Os tratamentos foram arranjados em esquema fatorial, cujo fator $A$ testou as diferentes zonas de manejos, e o fator $\mathrm{B}$ as intervenções de manejos. O fator zonas de manejo constou de 3 níveis considerados como zona de alta, zona de média e zona de baixa, já o fator intervenção de solo foi dividido em 4 níveis, sendo eles: pousio, escarificação, policultivo e escarificação+policultivo.

As intervenções no manejo de solo foram realizadas no dia 16 de junho de 2017, onde foi utilizado o escarificador FOX KS ${ }^{\circledR}$ da empresa Stara nos tratamentos que possuíam escarificação. O policultivo utilizado continha as culturas ervilhaca forrageira (Vicia sativa), nabo forrageiro (Raphanus sativus), centeio (Secale cereale) e aveia preta (Avena strigosa) que foram semeadas com as proporções de $25 \%$ cada espécie à lanço com densidade de $35 \mathrm{~kg} \mathrm{ha}^{-1}$.

Nos tratamentos que houveram mais de uma intervenção, a ordem dos procedimentos foi, primeira aplicação de gesso, em segundo escarificação e em seguida a semeadura das plantas de cobertura. Nos tratamentos onde houve somente duas intervenções em conjunto a ordem de execução permanece a mesma, somente excluindo o fator não utilizado.

A avaliação da densidade total de plantas daninhas e das diferentes espécies presentes na área deuse através de quantificação realizada no dia 20 de setembro de 2017, dez dias antes de ser realizado a dessecação para posterior semeadura da cultura de verão. Para isso, procedeu-se o levantamento mediante da contagem total do número de plantas daninhas, e separadamente por espécie, em quadrado metálico com lado de $1 \mathrm{~m}$, realizando-se três repetições para cada unidade experimental, para posterior cálculo da média de cada parcela. Os dados foram expressos em número de plantas $\mathrm{m}^{-2}$.

Com base nos dados quantitativos foram realizados os cálculos dos parâmetros fitossociológicos frequência relativa, densidade relativa, abundância relativa e índice de valor de importância. $O$ cálculo foi realizado com base nas equações propostas por (Mueller-Dombois e Ellenberg, 1974):

Frequência relativa (Frr) $=$ frequência $\times 100 /$ frequência total de todas espécies;

Densidade relativa $($ Der $)=$ densidade de espécies $\times 100 /$ densidade total das espécies;

Abundância relativa $(\mathrm{Abr})=$ abundância das espécies $\times$ 100/abundância total das espécies;

Índice de valor de importância $(\mathrm{IVI})=\mathrm{Frr}+\mathrm{Der}+\mathrm{Abr}$

Os cálculos da Frr, Der e Abr informam sobre a distribuição, quantidade e concentração da espécie, respectivamente, em relação às outras espécies encontradas na área amostrada. Já o índice de valor de importância (IVI) indica quais as espécies são mais importantes dentro da área em estudo. Os dados foram transformados pelo método: $\sqrt{\mathrm{x}+0,5}$ visto a não normalidade dos dados. Posteriormente, foi realizado a análise de variância (ANOVA) para as variáveis densidade total e por espécie plantas daninhas, sendo que quando foi verificado significância estatística, as médias foram comparados pelo teste Tukey $p<0,05$.

\section{Resultados e Discussão}

A análise da variância não evidenciou interação entre os fatores zonas de manejos e intervenções de manejo, o que indica que as zonas de manejos não influenciam nos efeitos das estratégias de manejo de solo sob a supressão de plantas daninhas. Assim, os resultados foram analisados em separados, quanto as zonas de manejos e das estratégias de manejos. 
A análise da fitossociologia das plantas daninhas identificou 6 espécies, as quais pertencem a 4 famílias botânicas, que são apresentadas na Tabela 4.

Tabela 3. P-valor para as espécies avaliadas em relação aos respectivos fatores.

\begin{tabular}{cccccccc}
\hline Fator & $\begin{array}{c}\text { Digitaria } \\
\text { sp. }\end{array}$ & $\begin{array}{c}\text { Sonchus } \\
\text { sp. }\end{array}$ & $\begin{array}{c}\text { Stachys } \\
\text { sp. }\end{array}$ & $\begin{array}{c}\text { Conyza } \\
\text { sp. }\end{array}$ & $\begin{array}{c}\text { Sida } \\
\text { sp. }\end{array}$ & $\begin{array}{c}\text { Gamochaeta } \\
\text { sp. }\end{array}$ & $\begin{array}{c}\text { Densidade de } \\
\text { plantas }\end{array}$ \\
\hline Zona de & 0.001 & $\mathrm{~ns}$ & 0.018 & $\mathrm{Ns}$ & $\mathrm{ns}$ & $\mathrm{ns}$ & 0.000 \\
manejo & $\mathrm{ns}$ & $\mathrm{ns}$ & $\mathrm{ns}$ & 0.006 & $\mathrm{~ns}$ & 0.000 & 0.004 \\
Intervenção & $\mathrm{ns}$ & $\mathrm{ns}$ & $\mathrm{ns}$ & $\mathrm{Ns}$ & $\mathrm{ns}$ & $\mathrm{ns}$ & $\mathrm{ns}$ \\
Zona Int. & $\mathrm{ns}$ &
\end{tabular}

ns = valores não significativos de P-valor a alfa 5\% de significância. Int: intervenção.

Tabela 4. Distribuição de plantas daninhas por família e por espécie encontradas nas áreas

$\begin{array}{cc}\text { Família } & \text { Nome científico } \\ \text { Asteraceae } & \text { Conyza bonariensis (CONBO) } \\ \text { Asteraceae } & \text { Gamochaeta pensylvanica (GNAPE) } \\ \text { Asteraceae } & \text { Sonchus oleraceus (SONOL) } \\ \text { Lamiaceae } & \text { Stachys arvensis (STAAR) } \\ \text { Malvaceae } & \text { Sida rhombifolia (SIDRH) } \\ \text { Poacea } & \text { Digitaria horizontalis (DIGSA) }\end{array}$

Nome popular
Buva
Macela
Seralha
Falsa hortelã
Guanxuma
Milhã

A sigla de cada espécie é provinda do código de classificação de BAYER

A família botânica Asteraceae apresentou maior número de espécies na área. Também se constatou a ocorrência de plantas cuja espécie está registrada com resistência a alguns herbicidas como a Conyza bonariensis (Heap, 2019).

Em relação à densidade de plantas daninhas a zona de baixa apresentou maior densidade de plantas daninhas comparado com as zonas de média e alta (Figura 2), que pode estar ligado a natural capacidade biológica das daninhas de crescerem e se estabelecerem em ambientes adversos, em contrapartida a cultura de interesse necessita de condições adequadas para crescer e ocupar a área, logo, as plantas daninhas favorecem-se nesta zona de menor potencial produtivo (Schneider et al., 2018; Brighenti e Oliveira, 2011). Ainda, pelo menor crescimento da cultura, limitando a sua capacidade de competir e suprimir o crescimento das plantas daninhas, favorecendo a segunda. Brighenti e Oliveira (2011) afirma que as plantas daninhas são demasiadamente competitivas, com características que garantem a perpetuação da espécie como elevada produção de sementes, raízes vigorosas, métodos de dispersão específicos de sementes e outros. Fialho et al. (2016) afirmam que as plantas daninhas são extremamente competitivas com a cultura, principalmente na redução do crescimento e absorção de nutrientes.

Quanto aos manejos de solo, pode ser observado na Figura 3 que as intervenções tiveram efeito na densidade de plantas daninhas. A intervenção que apresentou menor densidade de plantas daninhas foi Escarificação+Policultivos, diferindo do pousio em que quantificou-se cerca de $70 \%$ maior densidade de plantas daninhas. Voll et al. (2001) encontraram que o processo de escarificação gera um movimento no solo com hastes que rompem o solo em camadas subsuperficiais gerando alterações da infiltração de água e aeração causando alterações fisiológicas no banco de sementes. 

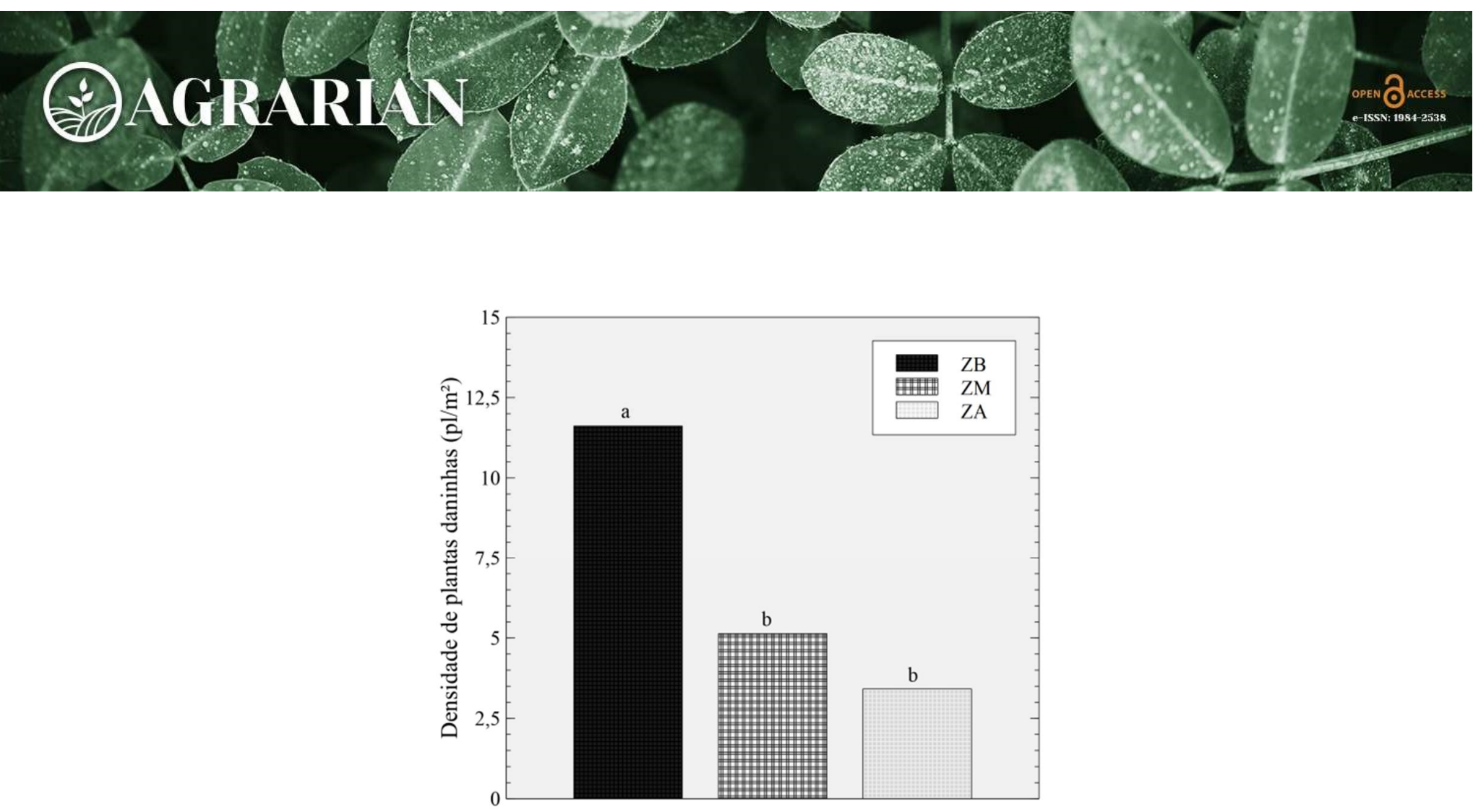

Zona de manejo

Figura 2. Densidade de plantas daninhas nas diferentes zonas de manejo

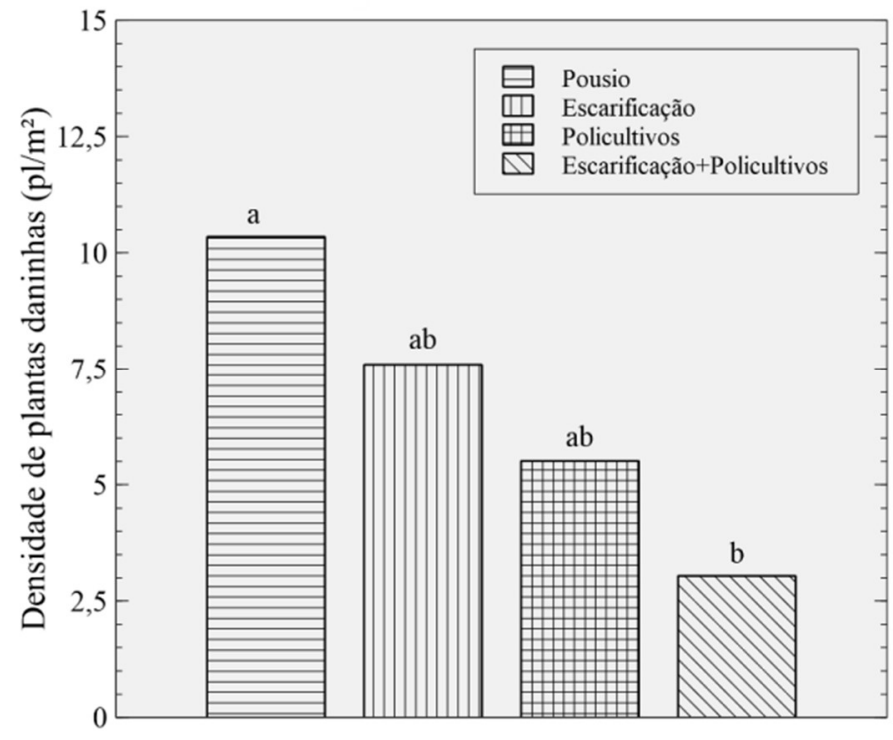

Intervenções

Figura 3. Densidade de plantas daninhas nas diferentes intervenções aplicadas

A utilização de policultivos de cobertura durante o inverno é uma prática que propicia o recobrimento total do solo com diferentes espécies, a cobertura causa um impedimento físico a germinação de sementes daninhas pelo sombreamento do solo e ocupação do espaço, e um impedimento biológico pela utilização dos recursos do local e pela liberação de compostos alelopáticos (Souza et al., 2006). Digitaria horizontalis e Conyza bonarinsis possuem fotoblastismo positivo, conforme encontrado por Klein e Felippe (1991). Compreender a maneira como o ambiente luminoso regula o término da dormência e as subsequentes germinações do banco 
de sementes, pode ser uma estratégia mais sustentável de controle de invasoras (Batlla \& Benech-Arnold, 2014).

De acordo com Tokura e Nobrega (2006), coberturas de aveia preta e nabo forrageiro possuem um potencial alelopático no controle de invasoras. O uso de consórcio de aveia preta, nabo forrageiro, ervilhaca e azevém apresentaram efeito negativo na emergência de soja, e isoladamente a cobertura de aveia preta e azevém também apresentaram efeito negativo na emergência de soja (Nobrega et al., 2009), sendo necessário uma dessecação antecipada à semeadura da soja.

Os valores de massa seca encontrados em média nestes policultivos foi de $2900 \mathrm{~kg}$.ha- ${ }^{-1}$. O conceito de policultivo é a adoção de espécies sobre um mesmo período na área, a características dessa prática é explorar os benefícios de cada uma das espécies e diversificar os sistemas radiculares que exploram o solo. Estudos comprovam que palha em decomposição pode liberar aleloquímicos, que, por sua vez, podem reduzir a emergência e, ou, o crescimento de plantas daninhas (Souza et al., 2006). Porém vale ressaltar que Lima et al. (2014) encontraram que coberturas de solo que apresentam baixa produção de massa vegetal permitiu o desenvolvimento de plantas daninhas, logo é importante investir em coberturas de solo com alto vigor e alta produção de massa vegetal. Por sua vez, o pousio é uma prática que deixa o solo exposto e permite que as plantas daninhas emerjam, cresçam e ocupem o espaço disponíveis podendo aumentar o banco de sementes ao completarem o ciclo de desenvolvimento. Lima et al. (2014) afirmam que a ausência de cobertura do solo, expõe o solo a luminosidade e logo favorece a germinação e desenvolvimento de invasoras para espécies fotoblásticas positivas.

O uso dos policultivos também gera incremento na produtividade da soja e aumento na biomassa de aveia preta, conforme aponta Pott et al. (2019). Forte et al. (2018) estudando a resposta da quantidade de massa seca em cobertura reportou relações positivas ao aumento de matéria seca e o controle de plantas daninhas.

Na Figura 4, estão representadas as densidades de cada espécie de plantas invasoras de acordo com o seu comportamento em cada zona de manejo. Inicialmente pode ser observado que cada espécie demonstrou um comportamento diferente em cada zona de manejo. Somente Digitaria horizontalis e Stachys arvensis apresentaram alta população de plantas daninhas na zona de baixo potencial produtivo, e os valores reduziramse conforme mudava a zona.

Pitelli e Durigan (2001) apontam que há três tipos de comportamento das plantas daninhas, as plantas tolerantes ao estresse que maximizam a extração de nutrientes e água em favor da sua manutenção, logo são bem adaptadas em ambientes menos férteis, plantas competidoras investem em crescimento de parte aérea e raízes com alta velocidade, porém não toleram ambientes altamente perturbados, e plantas ruderais, que investem na reprodução com ciclos rápidos porém não se adaptam em ambientes pouco férteis. Esse comportamento diferenciado que as plantas daninhas desenvolveram durante suas adaptações demonstra que o ambiente pode ser seletivo à determinadas espécies em função de suas características evolutivas, que permitem que elas estejam melhor adaptadas ou não ao mesmo. Assim, as zonas de manejo refletem exatamente esse contexto de diferenciações de ambiente e nicho ecológico para o desenvolvimento de espécies vegetais não melhoradas.

$\mathrm{Na}$ Figura 5, nota-se o efeito das intervenções sobre cada espécie de planta daninha. As espécies Digitaria sp., Sonchus sp., Stachys sp. e Sida sp. não apresentaram diferenças entre os métodos de manejo adotados durante o outono-inverno. 


\section{(2)AGrarian}

A
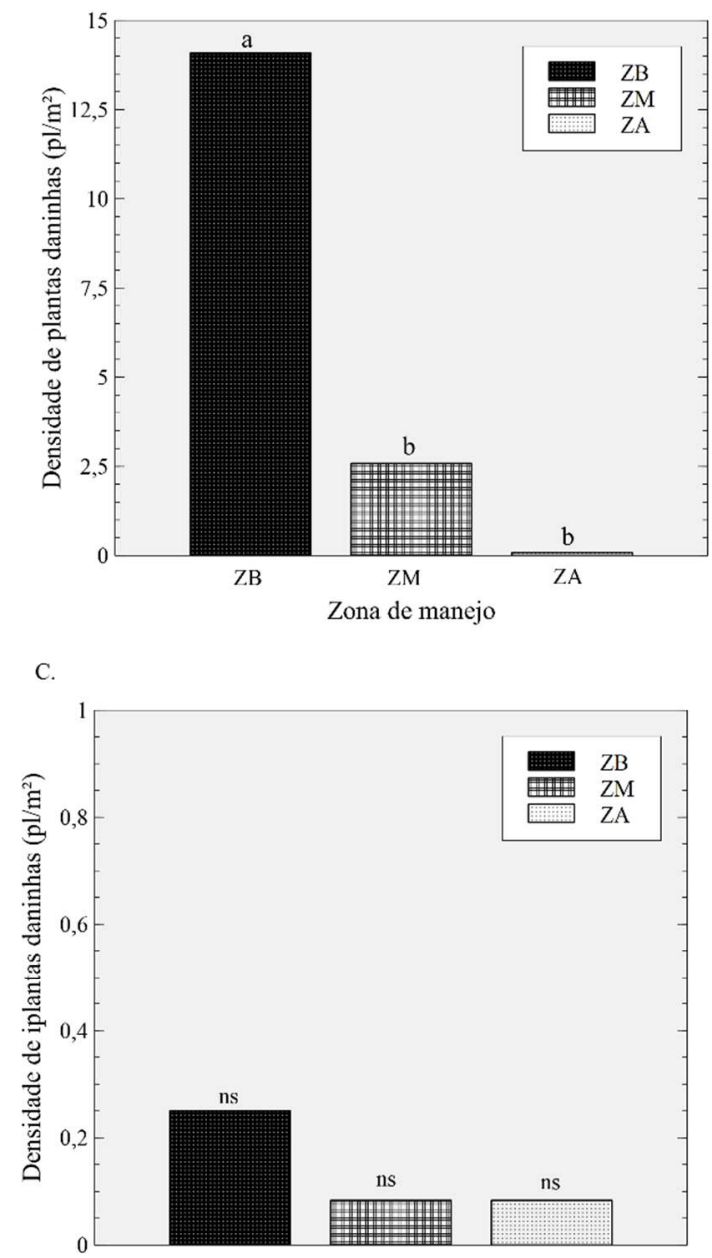

Zona de manejo

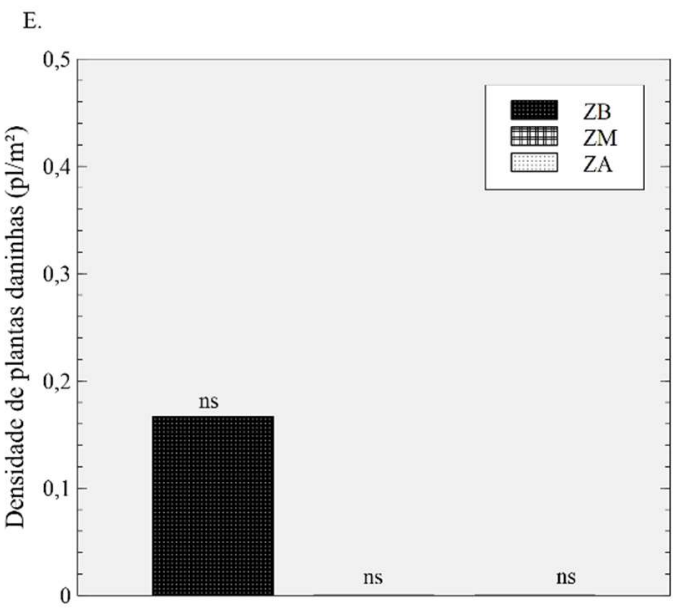

Zona de manejo
B.

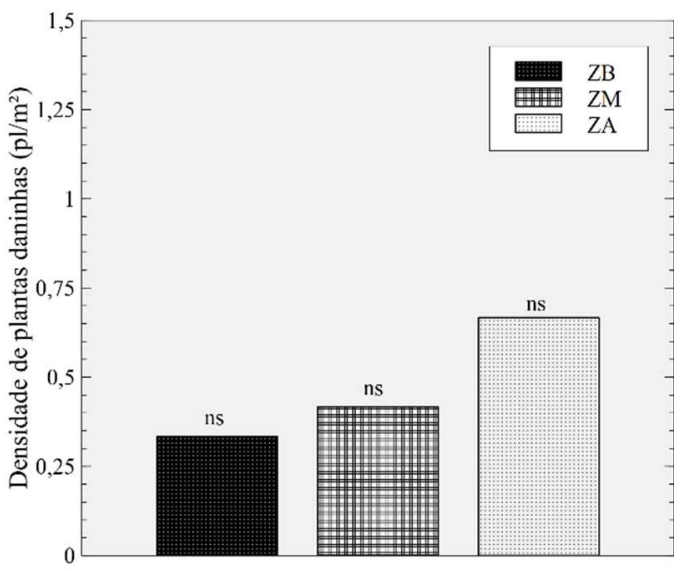

Zona de manejo

D

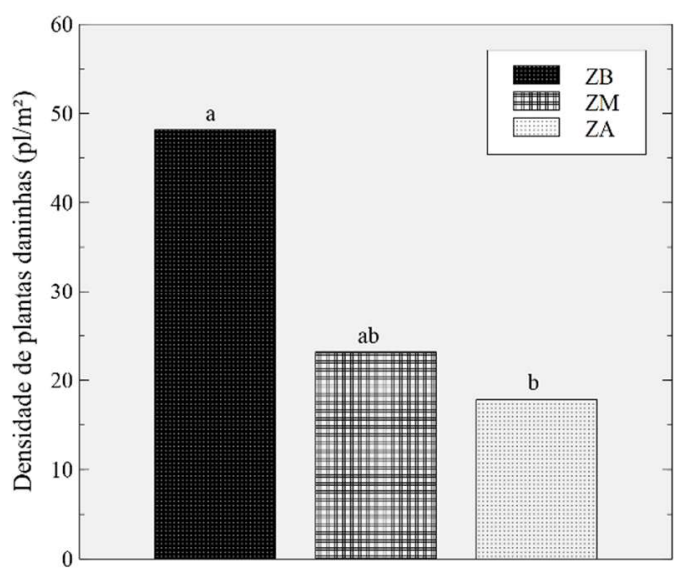

Zona de manejo

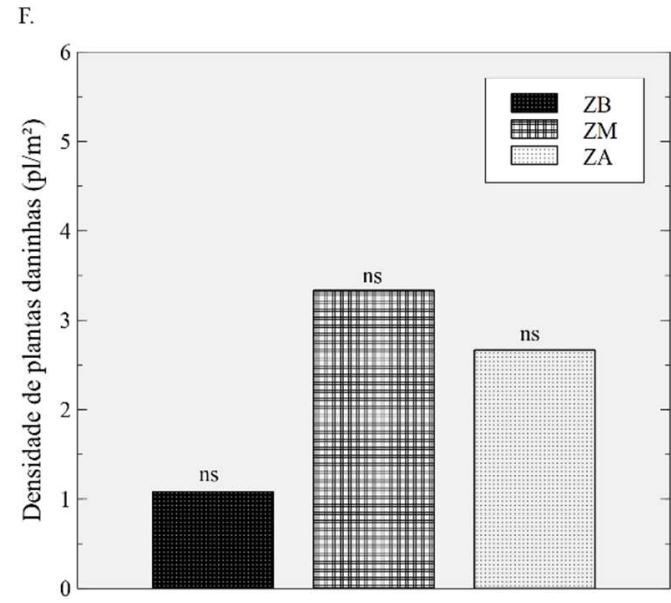

Zona de manejo

Figura 4. Comportamento da densidade de cada espécie de planta daninhas conforme a zona de manejo. A. Digitaria horizontalis, B. Sonchus oleraceus, C. Coniza bonariensis, D. Stachys arvensis, E. Sida rhombifolia, F. Gamochaeta pensylvanica

Agrarian, Dourados, v. 13, n. 47, p. 405-418, 2020.

cc) ()ㅇㅇㅣ 


\section{Oacrartan}

A.

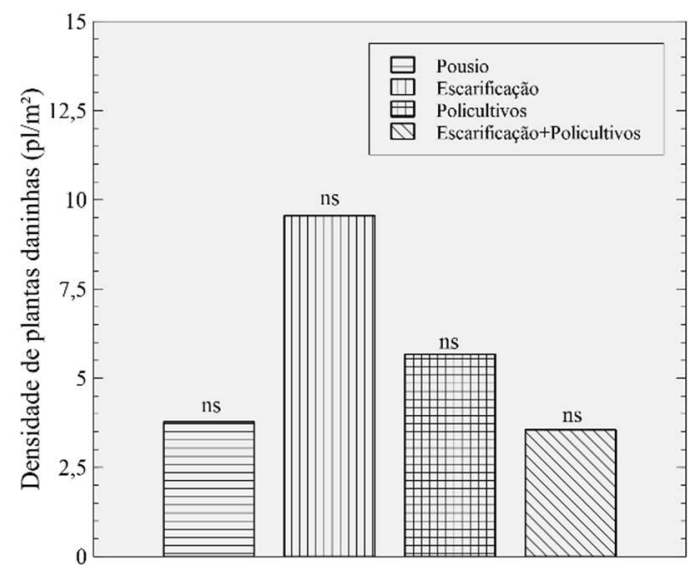

Intervenções

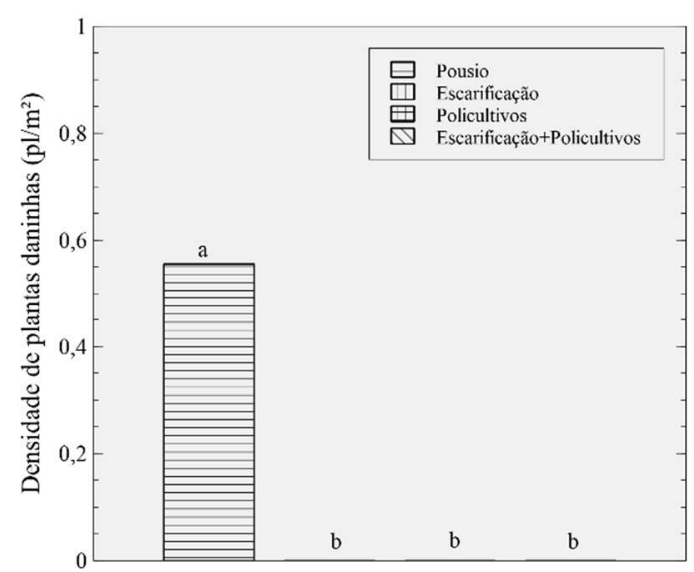

Intervenções

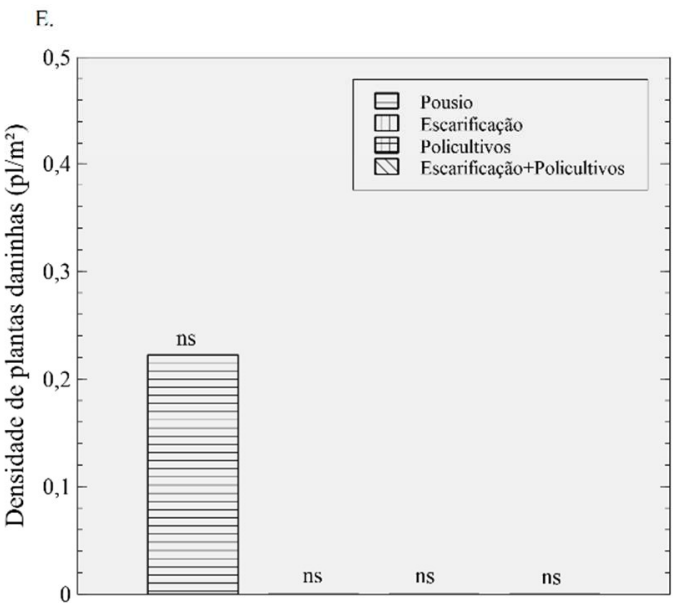

Intervenções

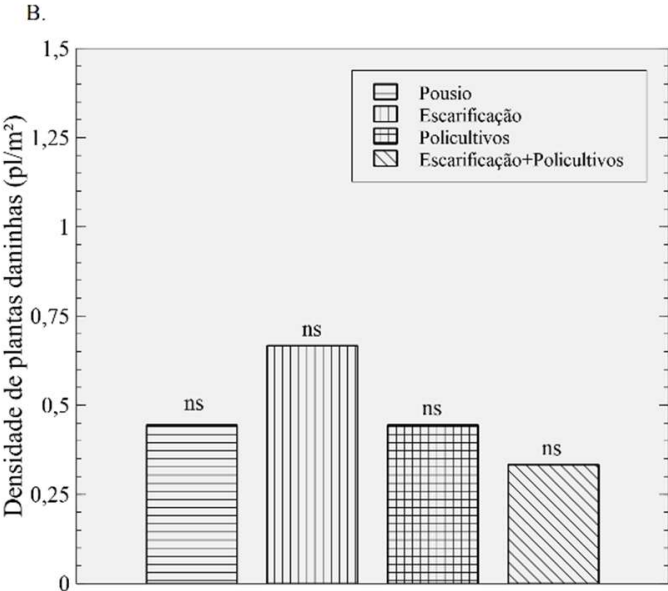

Intervenções

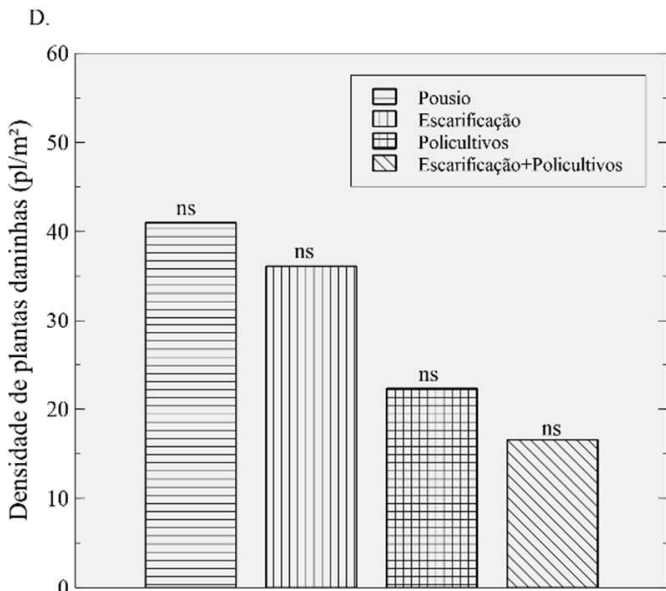

Intervenções

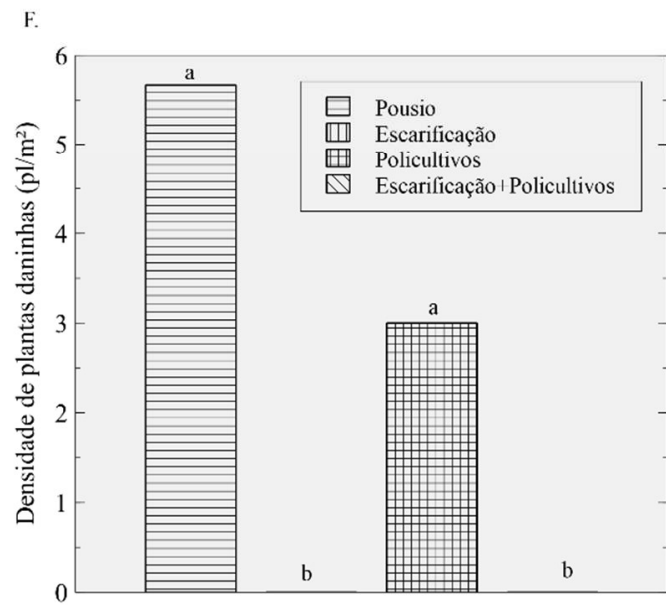

Intervenções

Figura 5. Densidade de plantas daninhas relacionado com as espécies encontradas em cada intervenção $A$. Digitaria horizontalis, B. Sonchus oleraceus, C. Coniza bonariensis, D. Stachys arvensis, E. Sida rhombifolia, F. Gamochaeta pensylvanica

Agrarian, Dourados, v. 13, n. 47, p. 405-418, 2020

(c) (1)(2) 
O uso de diferentes manejos de solo influi na presença de espécies daninhas, conforme apontam Forte et al. (2018). Para Conyza bonariensis, o efeito das intervenções foi significativo, os resultados encontrados que o uso de escarificação e policultivos são eficientes para o controle da espécie, pois está só desenvolveu alta densidade de plantas no pousio.

Destaca-se Gamochaeta pensylvanica, que demonstra não tolerar distúrbio, pois em ambas as intervenções que utilizaram escarificação não houve a incidência desta espécie, representando que a espécie pode apresentar-se como tolerante ao estresse, de acordo com sua estratégia evolucionária. Voll et al. (2001) encontraram que o processo de escarificação gera alterações fisiológicas no banco de sementes. Balbinot Junior e Veiga (2014) afirmam que houve maior densidade de dicotiledôneas em semeadura direta e em solo escarificado e a redução da presença de monocotiledôneas.

Estudos indicam que a cobertura do solo por plantas reduz a infestação da área com as sementes remanescentes de daninhas (Constantin et al., 2009). Pitelli e Durigan (2001) indicam que a plantas daninhas são dotadas de agressividade na ocupação de solos descobertos, porém são bastante sensíveis a presença de outras plantas no ambiente.

Tabela 5. Índices de Frequência Relativa, Densidade Relativa, Abundância Relativa e o Índice de Valor de Importância de cada zona de manejo

\begin{tabular}{lllll}
\hline Espécies & FRR & DER & ABR & IVI \\
\hline Zona de baixa & & & & \\
\hline Digitaria sp. & 25.000 & 15.157 & 15.321 & 55.478 \\
Sonchus sp. & 2.500 & 0.359 & 1.330 & 4.188 \\
Stachys sp. & 30.000 & 51.839 & 48.032 & 129.871 \\
Conyza sp. & 2.500 & 0.269 & 1.496 & 4.265 \\
Sida sp. & 2.500 & 0.179 & 1.994 & 4.674 \\
Gamochaeta sp. & 10.000 & 1.166 & 2.161 & 13.327 \\
Zona de média & & & & \\
\hline Digitaria sp. & 6.061 & 6.288 & 16.692 & 29.041 \\
Sonchus sp. & 6.061 & 1.014 & 1.432 & 8.507 \\
Stachys sp. & 33.333 & 56.389 & 52.078 & 141.801 \\
Conyza sp. & 0.000 & 0.203 & 1.074 & 1.277 \\
Sida sp. & 0.000 & 0.000 & 0.000 & 0.000 \\
Gamochaeta sp. & 15.152 & 8.114 & 3.042 & 26.307 \\
Zona de alta & & & & \\
\hline Digitaria sp. & 3.704 & 1.000 & 16.108 & 20.812 \\
Sonchus sp. & 7.407 & 2.667 & 1.655 & 11.729 \\
Stachys sp. & 44.444 & 62.667 & 51.395 & 158.506 \\
Conyza sp. & 0.000 & 0.333 & 0.000 & 0.333 \\
Sida sp. & 0.000 & 0.000 & 0.000 & 0.000 \\
Gamochaeta sp. & 14.815 & 8.333 & 5.516 & 28.665 \\
\hline FR Frequen & a & & & \\
\hline
\end{tabular}

FRR= Frequência Relativa, DER= Densidade Relativa, ABR= Abundância Relativa, IVI= Índice de Valor da Importância.

Na comparação entre zonas, Tabela 5, é possível notar que cada zona possui espécies com maior ou menor valor de IVI, indicando que cada zona possui atributos que favorecem o desenvolvimento de certas espécies e ao mesmo tempo desfavorecem outras espécies de plantas daninhas. A espécie de maior Índice Valor de Importância em todas as zonas é Stachys sp., e Gamochaeta sp. é a espécie que ganha maior importância nas zonas de média e alta, enquanto Digitaria sp. ganha destaque na zona de baixa o que pode ser devido as características de adaptação à ambiente com menor disponibilidade de recursos. 
Outro ponto importante a observar nesta Tabela 5 é a presença de Sida sp. somente na zona de baixo potencial. O comportamento das espécies Stachys sp., Sonchus sp., Gamochaeta sp. em que aumentaram seu IVI da Zona Baixa e Média para a Alta, o que indica uma adaptação destas espécies a condições melhores de solo e ambiente. E o inverso para as espécies Digitaria sp. e Conyza sp., que diminuíram seu IVI das Zona de Baixa, Média e Alta, indicando que são espécies adaptadas a ambientes não tão favoráveis ou do efeito supressivo da cobertura. Ferreira et al. (2019) encontraram respostas a análise fitossociológica de plantas daninhas oscilando conforme os teores de adubação adicionados na área de cultivo.

Tabela 6. Índices de Frequência Relativa, Densidade Relativa, Abundância Relativa e o Índice de Valor de Importância de cada intervenção

\begin{tabular}{lllll}
\hline Espécies & FRR & DER & ABR & IVI \\
\hline Pousio & & & & \\
\hline Digitaria sp. & 11.905 & 4.564 & 7.243 & 23.712 \\
Sonchus sp. & 7.143 & 0.537 & 1.420 & 9.100 \\
Stachys sp. & 21.429 & 49.530 & 43.671 & 114.630 \\
Conyza sp. & 9.524 & 0.671 & 1.331 & 11.526 \\
Sida sp. & 2.381 & 0.268 & 2.130 & 4.780 \\
Gamochaeta sp. & 21.429 & 6.846 & 6.036 & 34.310 \\
Escarificação & & & & \\
\hline Digitaria sp. & 21.429 & 15.722 & 18.272 & 55.423 \\
Sonchus sp. & 10.714 & 1.097 & 2.550 & 14.361 \\
Stachys sp. & 32.143 & 59.415 & 46.034 & 137.592 \\
Conyza sp. & 0.000 & 0.000 & 0.000 & 0.000 \\
Sida sp. & 0.000 & 0.000 & 0.000 & 0.000 \\
Gamochaeta sp. & 0.000 & 0.000 & 0.000 & 0.000 \\
Policultivos & & & & \\
\hline Digitaria sp. & 9.375 & 12.846 & 27.979 & 50.200 \\
Sonchus sp. & 9.375 & 1.008 & 2.194 & 12.577 \\
Stachys sp. & 25.000 & 50.630 & 41.351 & 116.981 \\
Conyza sp. & 0.000 & 0.000 & 0.000 & 0.000 \\
Sida sp. & 0.000 & 0.000 & 0.000 & 0.000 \\
Gamochaeta sp. & 21.875 & 6.801 & 6.348 & 35.024 \\
Escarificação+Policultivo & & & & \\
\hline Digitaria sp. & 9.524 & 14.612 & 37.598 & 61.734 \\
Sonchus sp. & 9.524 & 1.370 & 3.525 & 14.418 \\
Stachys sp. & 42.857 & 68.037 & 38.903 & 149.797 \\
Conyza sp. & 0.000 & 0.000 & 0.000 & 0.000 \\
Sida sp. & 0.000 & 0.000 & 0.000 & 0.000 \\
Gamochaeta sp. & 0.000 & 0.000 & 0.000 & 0.000 \\
\hline FRR Fren & & & & \\
\hline & & & & \\
\hline
\end{tabular}

FRR= Frequência Relativa, DER= Densidade Relativa, ABR= Abundância Relativa, IVI= Índice de Valor da Importância

Pode-se notar, que no pousio houve a maior diversidade de espécies, Frequência, Densidade e Abundância relativa e Índice de Valor de Importância se comparado aos demais tratamentos. Confirmando os dados debatidos anteriormente.

Interessante ressaltar que o efeito isolado de uso de escarificação e de policultivos, foi encontrado também no uso das duas práticas. Mas as espécies encontradas no uso consorciado de escarificação e 
policultivo apresentaram valores de IVI maiores que nas demais intervenções. O que indica que as intervenções realizadas não são eficientes no controle de Digitaria sp., Sonchus sp., e Stachys sp.

Outra observação é que tanto Conyza sp. quanto Sida sp. são susceptíveis as intervenções de escarificação e policultivo em igual grau. Já Gamochaeta sp. demonstrou ser susceptível somente à escarificação. Ulguim et al. (2018) encontraram diferentes análises fitossociológicas conforme a intervenção utilizada na área para o estudo. Forte et al. (2018) também encontraram diferenças na análise fitossociologia das plantas daninhas com diferentes manejos adotados e em diferentes safras.

O estudo de práticas que visem a redução da infestação de plantas daninhas deve contemplar as diversidades dessas espécies extremamente agressivas. As plantas daninhas são espécies adaptadas para competir e se desenvolver em diferentes ambientes, e por isso, o estudo de zonas de diferentes atributos pode gerar informações importantes sobre as características dessas plantas, podendo o uso de intervenções mecânicas, físicas e químicas gerarem reações diversas das diferentes espécies, e para que os produtores possam adotar manejos mais eficientes, dados de controle isolados devem ser levantados.

\section{Conclusão}

As utilizações dos métodos de intervenção de solo foram eficientes na redução de populações de plantas daninhas infestantes. A utilização de escarificação e uso de plantas de cobertura diminuíram a densidade de espécies infestantes.

\section{Referências}

ALVARES, C. A.; STAPE, J. L.; SENTELHAS, P. C.; DE MORAES, G.; LEONARDO, J.; SPAROVEK, G. Köppen's climate classification map for Brazil. Meteorologische Zeitschrift, v. 22, n. 6, p. 711-728, 2013. https://doi.org/10.1127/0941-2948/2013/0507

BATLLA, D.; BENECH-ARNOLD, R. L. Weed seed germination and the light environment: Implications for weed management. Weed Science Society of Japan, v. 14, p. 77-87, 2014.

BRIGHENTI, A. M.; OLIVEIRA, M. F. de. Biologia de plantas daninhas. Curitiba: Omnipax, 2011. p. 1-36.

CONSTANTIN, J.; RUBEM, J. S. DE O.; INOUE, M.H.; CAVALIERI, S.D.; ARANTES, J.G.Z. Sistemas de manejo de plantas daninhas no desenvolvimento e na produtividade da soja. Bragantia, v. 68, n. 1, p. 125-135, 2009. http://dx.doi.org/10.1590/S0006-87052009000100014

FERREIRA, E. A.; PAIVA, M.C.G.; PEREIRA, G.A.M.; OLIVEIRA, M.C.; DE BARROS, S.E. Fitossociologia de plantas daninhas na cultura do milho submetida à aplicação de doses de nitrogênio. JOURNAL OF NEOTROPICAL AGRICULTURE, v. 6, n. 2, p. 100-107, 2019. https://doi.org/10.32404/rean.v6i2.2710

FIALHO, C.M.T.; SILVA, G.S.D.; FAUSTINO, L.A.; CARVALHO, F.P.D.; COSTA, M.D.; SILVA, A.A.D. Associação micorrízica em soja e plantas daninhas em competição. Acta Sci., Agron., Maringá, v. 38, n. 2, p. 171-178, 2016. https://dx.doi.org/10.4025/actasciagron.v38i2.27230.

FORTE, C. T.; GALON, L.; BEUTLER, A. N.; REICHERT JR, F. W.; MENEGAT, A. D.; PERIN, G. F.; TIRONI, S. P. Cultivation Systems, Vegetable Soil Covers and their Influence on the Phytosocyology of Weeds. Planta Daninha, v. 36, 2018. http://dx.doi.org/10.1590/s0100-83582018360100099

SANTOS, H. G.; JACOMINE, P. K. T.; DOS ANJOS, L. H. C.; DE OLIVEIRA, V. A.; LUMBRERAS, J. F.; COELHO, M. R.; ALMEIDA, J. A.; FILHO, J. C. A.; DE OLIVEIRA, J. B.; CUNHA, T. J. F.. Sistema Brasileiro de Classificação de Solos (SiBCS). 3.ed. Brasília, DF, Embrapa,. 2013. p. 353.

HAUSCHILD, F. E. G.; et al. Técnicas de agricultura de precisão para definição de zonas de manejo de solo. Santa Maria - UFSM, 2013. Dissertação de Mestrado. 
HEAP, I. Internacional survey of herbicide resistant weeds. The International Herbicide-Resistant Weed Database. Disponível em: http://www. weedscience. org. Acesso em: 23/12/2019

BALBINOT JUNIOR, A. A.; DA VEIGA, M. Densidade de plantas daninhas afetada por sistemas de manejo do solo e de adubação. Revista de Ciências Agroveterinárias, v. 13, n. 1, p. 47-55, 2014.

KLEIN, A.; FELIPPE,G.M. Efeito da luz na germinação de sementes de ervas invasoras. Pesquisa Agropecuária Brasileira. v 27, n 7, p 955-966, 1991.

KUCHLER, A.W.; MUELLER-DOMBOIS, D.; ELLENBERG, H. The Count-Plot Method and Plotless Sampling Techniques. Aims and Methods of Vegetation Ecology, p. 67-92, 1974.

LIMA, S. F.; TIMOSSI, P. C. Interferência de plantas daninhas no desenvolvimento de Fabaceas perenes. Revista Verde, v. 9, n. 4, p. 129-136, 2014.

NÓBREGA, L. H. P.; LIMA, G. P.; MARTINS, G. I.; MENEGHETTI, A. M. Germinação de sementes e crescimento de plântulas de soja (Glycine max L. Merrill) sob cobertura vegetal. Acta Scientiarum Agronomy, v. 31, n. 3, p. 461-465, 2009. DOI: 10.4025/actasciagron.v31i3.320

OLIVEIRA NETO, A. M.; CONSTANTIN, J.; OLIVEIRA, J. R. S.; GUERRA, N.; DAN, H. A.; ALONSO, D. G.; BLAINSKI E.; SANTOS G. Estratégias de manejo de inverno e verão visando ao controle de Conyza bonariensis e Bidens pilosa. Planta Daninha, v. 28, n. 5, p. 1107-1116, 2010. http://dx.doi.org/10.1590/S010083582010000500018.

PITELLI, R. A. O termo planta-daninha. Planta Daninha, v. 33, n. 3, p. 622-623, 2015. http://dx.doi.org/10.1590/S0100-83582015000300025

PITELLI, R. A.; DURIGAN, J. C. Ecologia das plantas daninhas no sistema de plantio direto. Rossello, RD Siembra directa en el cono sur. Montevideo: PROCISUR, p. 203-210, 2001.

POTT, L. P.; AMADO, T. J. C.; LEAL, O. A.; Ciampitti, I.A. Mitigation of soil compaction for boosting crop productivity at varying yield environments in southern Brazil. European Journal of Soil Science, 1-16, 2019. https://doi.org/10.1111/ejss.12880

SÃO MIGUEL, A. S. D. C.; PACHECO, L. P.; SOUZA, E.; SILVA, C. M. R.; CARVALHO, I. C. Cover Crops in the Weed Management in Soybean Culture. Planta Daninha, v. 36, 2018. http://dx.doi.org/10.1590/s010083582018360100072

SCHNEIDER, T.; RIZZARDI, M. A.; NUNES, A. L.; BIANCHI, M. A.; BRAMMER, S. P.; ROCKENBACH, A. P. Biologia molecular aplicada à ciência das plantas daninhas. Revista Brasileira de Herbicidas, v. 17, n. 1, p. 12-24, 2018. http://dx.doi.org/10.7824/rbh.v1i1.523

SILVA HIRATA, A. C.; HIRATA, E. K.; MONQUERO, P. A.; GOLLA, A. R.; NARITA, N. Plantas de cobertura no controle de plantas daninhas na cultura do tomate em plantio direto. Planta Daninha, v. 27, n. 3, p. 465-472, 2009.

SOUZA, L. S.; VELINI, E. D.; MARTINS, D.; ROSOLEM, C. A. Efeito alelopático de capim-braquiária (Brachiaria decumbens) sobre o crescimento inicial de sete espécies de plantas cultivadas. Planta daninha, p. 657-668, 2006. http://dx.doi.org/10.1590/S0100-83582006000400006

TOKURA, L. K.; NÓBREGA, L. H. P. Alelopatia de cultivos de cobertura vegetal sobre plantas infestantes. Acta Scientiarum Agronomy, v. 28, n. 3, p. 379-384, 2006.

ULGUIM, A. D. R.; CARLOS, F. S.; SANTOS, R. A. D. S.; ZANON, A. J.; WERLE, I. S.; BECK, M. Weed phytosociological in irrigated rice under different cultivation systems and crop rotation intensity. Ciência Rural, v. 48, n. 11, 2018. http://dx.doi.org/10.1590/0103-8478cr20180230 
